\title{
Atypical enteritis causing life-threatening pneumatosis intestinalis in a dog - radiographic and ultrasonographic findings
}

\author{
Atypische enteritis die levensbedreigende pneumatosis intestinalis veroorzaakt \\ bij een hond - radiografische en echografische bevindingen
}

\author{
${ }^{1}$ G. Mampaey, ${ }^{1}$ G. Schils, ${ }^{1}$ A. Schlake, ${ }^{1}$ S. Marynissen, ${ }^{2}$ E. Vandermeulen
}

${ }^{1}$ Small Animal Department, Faculty of Veterinary Medicine, Ghent University, Merelbeke, Belgium ${ }^{2}$ Department of Medical Imaging of Domestic Animals, Faculty of Veterinary Medicine, Ghent University, Merelbeke, Belgium

gitte.mampaey@ugent.be



\section{SAMENVATTING}

Een geriatrische hond werd aangeboden met klachten van acuut braken, anorexie en lethargie. Tijdens het abdominale echografisch onderzoek werd de aanwezigheid van gas in de wand van de dunne darm aangetoond. Via abdominale radiografieën werden de echografische afwijkingen bevestigd, die compatibel bleken met pneumatosis intestinalis. Tijdens exploratieve laparotomie werden hemorragische laesies, verdikte darmwanden en een serosale verkleuring van het jejunum waargenomen. Partiële jejunectomie werd uitgevoerd. De resultaten van het histopathologisch onderzoek beschreven atypische bacteriële enteritis. De hond herstelde volledig en vertoonde geen klinische symptomen meer gedurende een opvolgingsperiode van één jaar.

\section{INTRODUCTION}

Pneumatosis intestinalis $(\mathrm{PI})$ is an uncommon radiologic finding in humans (Palamidessi, 2011), which has been reported as the presence of air or gas in the submucosa or subserosa of the small intestines (Degner, 1992; Morris, 1992; Pear, 1998; Aste et al., 2005; Song et al., 2013).

In human medicine, PI is subdivided in two groups primary PI, which is benign in nature, and secondary PI, which reflects a pathological, often life-threatening condition (Mitsuyoshi, 2015), requiring aggressive surgical and medical treatment (Hwang et al., 2016;
Rajan et al., 2017). In primary PI, intramural gas creates a circular or cystic air pattern within the small intestinal wall, called pneumatosis cystoides intestinalis (Pear, 1998; Ho et al., 2007). In secondary PI, gas accumulates as a nodular or linear pattern within the small intestinal walls (Hwang et al., 2016; Rajan et al., 2017). In the majority of cases, the differentiation can be made based on ultrasound or radiography, although computed tomography is considered as the gold standard (Di Pietropaolo, 2020). Gas accumulation is more commonly seen in other organs, such as the wall of the stomach in gastric pneumatosis and emphysematous gastritis or in the wall of the large 
intestines in pneumatosis coli (PC) (Degner, 1992; Morris, 1992; Choi, 2009; Aste et al., 2005; Hwang, 2016).

To the authors' knowledge, primary PI and secondary PI each have been reported only once in dogs (Hedgespeth and Pérez, 2017; Song et al., 2013). In cats, life-threatening PI has been described in two case reports, respectively caused by idiopathic emphysematous hepatitis and a clostridium difficile infection (Hutchinson et al., 2018; Walczak, 2018). In this case report, the imaging findings are described of a dog with secondary PI who survived after aggressive surgical and medical treatment, which underlines the need for awareness of this condition.

\section{CASE DESCRIPTION}

\section{Signalment, history and clinical findings}

A twelve-year-old, spayed, female Labrador retriever was referred to the emergency service (Ghent University, Faculty of Veterinary Medicine, Small Animal Department, Merelbeke, Belgium) with com- plaints of anorexia, vomiting and lethargy for five days. The dog had no prior medical history. She received one subcutaneous injection of hyoscine butylbromide/ metamizol sodium (Buscopan compositum $\AA$, Boehringer Ingelheim, the Netherlands) and one intramuscular injection of prednisolone $0.6 \mathrm{mg} / \mathrm{kg}$ (Prednisol $2,5 \% \AA$, UDD diergeneesmiddel, the Netherands) prior to referral.

Upon presentation, abnormal physical examination findings included lethargy, mild tachycardia (140 bpm), prolonged capillary refill time and weak femoral pulse. The dog showed mild discomfort on abdominal palpation and was moderately dehydrated. Digital rectal examination demonstrated marked hematochezia. The patient was normotensive and normoglycemic.

The results of the blood examination obtained by the referring veterinarian prior to referral, revealed mild leukocytosis, mild anemia, mild hypoproteinemia, hypoalbuminemia, increased DGGR lipase and increased C-reactive protein (Tables 1 and 2).

Complete blood count was repeated at presentation and revealed moderate non-regenerative anemia and moderate leukocytosis (Table 2). Prothrombintime(PT)

Table 1. Serum biochemistry values at the referring veterinarian.

\begin{tabular}{lcc}
\hline Parameter & Value at the referring vet & Reference interval \\
\hline Albumin & 23.4 & $28-38 \mathrm{~g} / \mathrm{L}$ \\
Total protein & 46.6 & $58-75 \mathrm{~g} / \mathrm{dL}$ \\
ALP (Alkaline phosphatase) & 208 & $10-50 \mathrm{U} / \mathrm{L}$ \\
ALT (Alanine aminotransferase) & 19 & $25-55 \mathrm{U} / \mathrm{L}$ \\
AST (Aspartate aminotransferase) & 21 & $15-30 \mathrm{U} / \mathrm{L}$ \\
Total bilirubin & $<2.75$ & $<2.75 \mu \mathrm{mol} / \mathrm{L}$ \\
Bile acids & 6 & $<20 \mu \mathrm{mol} / \mathrm{L}$ \\
DGGR Lipase & 201 & $<125 \mathrm{U} / \mathrm{L}$ \\
BUN (Blood urea nitrogen) & 3.4 & $2.0-6.7 \mathrm{mmol} / \mathrm{L}$ \\
Creatinine & 46.85 & $27-106 \mu \mathrm{mol} / 1$ \\
Total calcium & 2.15 & $2.10-3.00 \mathrm{mmol} / \mathrm{L}$ \\
Phosphorous & 1.50 & $0.90-1.60 \mathrm{mmol} / \mathrm{L}$ \\
Cholesterol & 6.7 & $2.5-6.0 \mathrm{mmol} / \mathrm{L}$ \\
C-Reactive protein & 174.5 & $<10 \mathrm{mg} / \mathrm{L}$ \\
\hline
\end{tabular}

Table 2. CBC results obtained at the referring veterinarian at presentation and three days after enterectomy.

\begin{tabular}{lcccc}
\hline Parameter & $\begin{array}{c}\text { At referring } \\
\text { veterinarian }\end{array}$ & $\begin{array}{c}\text { At } \\
\text { presentation }\end{array}$ & $\begin{array}{c}\text { Three days } \\
\text { post-operative }\end{array}$ & $\begin{array}{c}\text { Reference } \\
\text { interval }\end{array}$ \\
\hline Hemoglobin & 12.89 & 9.9 & 8.9 & $13.1-20.5 \mathrm{~g} / \mathrm{dl}$ \\
Hematocrit & 35.7 & 25.8 & 24.1 & $37.3-61.7 \%$ \\
Platelet count & 304 & 341 & 354 & $148-484 \mathrm{~K} / \mu \mathrm{L}$ \\
Mean corpuscular volume & 64 & 57.8 & 59.2 & $61.6-73.5 \mathrm{fL}$ \\
Mean corpuscular hemoglobin concentration & 35.45 & 38.4 & 36.9 & $32.0-37.9 \mathrm{~g} / \mathrm{dl}$ \\
Absolute reticulocytes & $/$ & 21.4 & 38.3 & $10.0-110.0 \mathrm{~K} / \mu \mathrm{L}$ \\
White blood cells & 18.04 & 25.16 & 24.83 & $5.05-16.76 \times 10^{9} / 1$ \\
Neutrophils & 13.53 & 0.18 & 0.19 & $2.95-11.64 \times 10^{9} / 1$ \\
Lymphocytes & 1.6 & 9.86 & 22.45 & $1.05-5.10 \times 10^{9} / 1$ \\
Monocytes & 2.71 & 14.86 & 1.79 & $0.16-1.12 \times 10^{9} / 1$ \\
Eosinophils & 0.18 & 0.16 & 0.23 & $0.06-1.23 \times 10^{9} / 1$ \\
\hline
\end{tabular}


and partial thromboplastin time (aPTT) were measured and were within normal reference range. Lactate was within normal limits.

\section{IMAGING, DIAGNOSIS AND OUTCOME}

\section{Abdominal ultrasound}

Abdominal ultrasound was elected as primary imaging modality. The main abnormalities were related to the gastrointestinal tract. The stomach was moderately filled with a mixture of gas and fluid content; no peristaltic movements or contractions were noted during the investigation, indicating a possible functional ileus. The gastric wall thickness and layering remained normal. In the mid- to caudal abdomen, a large section of the jejunum demonstrated corrugation and loss of normal layering. The alterations in the wall made it difficult to reliably identify the inner layers of the affected jejunal wall, although the serosal surface and adjacent hypoechoic muscularis layer seemed intact. More centrally, the submucosal layer and mucosal layer, normally identifiable as a hyperechoic and hypoechoic layer respectively, could not be delineated properly. At this level, a strongly hyperechoic and irregular interface was noted. Distal from this, a strong inhomogeneous shadow artefact or 'dirty shadow' was created, indicating abnormal gas content in the more central mural layers. The presence of this artefact hampered assessment of the entire jejunal wall at this level (Figure 1).

There was no evidence of perforation of the jejunal wall and the adjacent mesenteric fat was within normal limits. The jejunum immediately proximal and distal to this lesion had a normal appearance and diameter, thereby excluding complete mechanical obstruction. The other intestinal segments demonstrated normal wall layering, thickness and content.

A moderately enlarged liver with a homogeneous, mildly hyperechoic parenchyma was noticed. Dissecting between the liver lobes and surrounding the gall bladder, a small amount of anechoic free fluid was seen, and aspiration of the fluid was performed. Cytologic examination of this localized effusion yielded a non-septic modified transudate.

Other abdominal organs were within normal limits. As the intramural gas of the jejunum prohibited further evaluation, abdominal radiographs were elected as adjuvant imaging technique.

\section{Abdominal radiography}

On the abdominal radiographs, a linear intramural gas opacity was seen in a part of the jejunal loops, parallel with the serosal surface, suspected to be at the level of the more central layers (mucosa and submucosa). At several locations, this linear gas opacity had a mildly undulating appearance, possibly consistent with minimal peristaltism or simply following

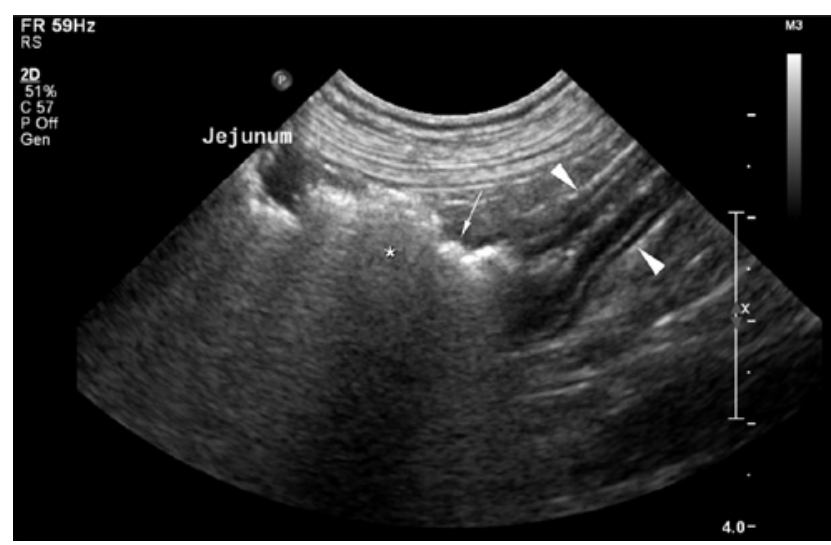

Figure 1. Abdominal ultrasound showing abnormal presence of presumed intramural gas in a segment of the jejunal wall and loss of wall layering (white arrow), in continuation with a normal jejunal segment (white arrowheads). The intramural gas creates an irregular distal acoustic shadow artefact (asterisk).



Figure 2. Ventrodorsal radiograph of the abdomen showing linear and irregular accumulations of gas within the small intestinal wall.

the conformation of the jejunal loop, while in other segments, it appeared straighter. A heterogeneous soft tissue material was visible within the lumen, with few gas bubbles dispersed within this material (Figures 2, 3 and 4).

A second jejunal loop, located in the cranioventral abdomen, was gas dilated and seemed corrugated. This segment was markedly shorter than the previous- 


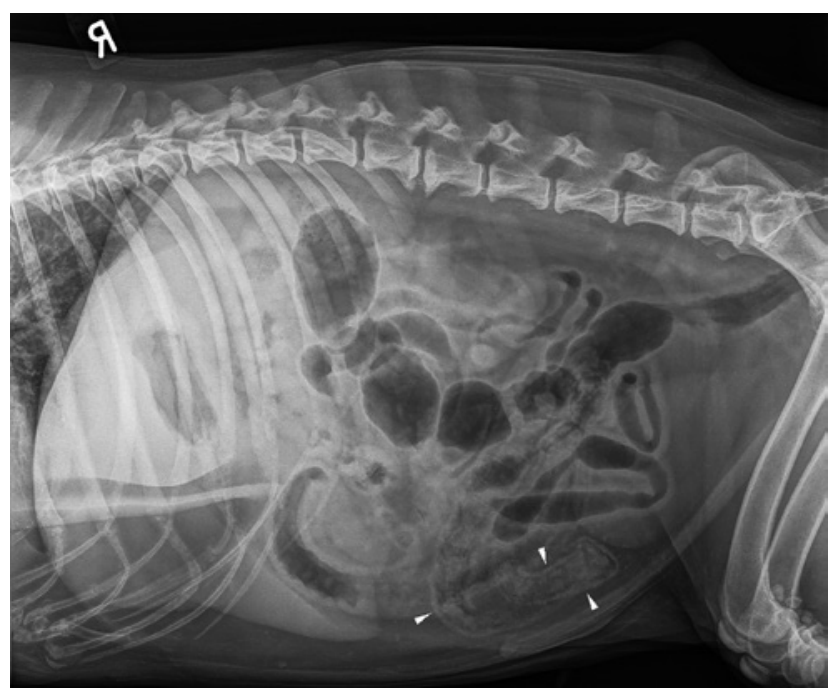

Figure 3. Right lateral radiograph of the abdomen showing gas lucencies within the small intestinal wall.

ly described abnormal segment. A large portion of the gastrointestinal system was either empty or gas filled showing no evidence of an intestinal obstruction.

A mild to moderate loss of serosal detail was noted in the mid- to cranial abdomen, which could be attributed to the mild peritoneal effusion.

In conclusion, the preliminary diagnosis was jejunal PI. As differential cause of the jejunal wall alterations, a foreign object/neoplasia or bacterial enteritis with gas forming bacteria such as clostridium were postulated. A computed tomography scan was considered an adjunctive diagnostic tool, but explorative laparotomy was elected in order to allow diagnosis via histopathologic samples and treatment simultaneously.

\section{Enterectomy and histopathology}

Anesthesia was induced with midazolam $0.3 \mathrm{mg} /$ $\mathrm{kg}$ (Midazolam ${ }^{\circledR}$, Mylan, Belgium) and alfaxalone $3 \mathrm{mg} / \mathrm{kg}$ (Alfaxan ${ }^{\circledR}$, Jurox, United Kingdom). Afterwards, the dog was intubated and anesthesia was maintained using isoflurane (Isoflo®, Zoetis, Belgium). A continuous infusion of Fentanyl $5 \mu \mathrm{g} / \mathrm{kg} / \mathrm{min}$ (Fentadon $\AA$, Dechra, the Netherlands) and lidocaine $30 \mu \mathrm{g} / \mathrm{kg} / \mathrm{min}$ (Lidor ${ }^{\circledR}$, Richter Pharma, Austria) was used to manage pain. Because of hypotension, a continuous infusion of norepinephrine was started after the administration of boli of crystalloids. Eventually, the dog received fresh frozen plasma during surgery because of constant low arterial blood pressure likely due to low colloid-oncotic pressure.

While inspecting the abdominal content, a hemorrhagic lesion in the pylorus and duodenum and a thickened mesenteric intestinal wall in the proximal part of the jejunum were noticed. This part shaded into a 30 $\mathrm{cm}$ intestine segment with a thickened wall and abnormal color; $20 \mathrm{~cm}$ caudal to this part, another $7 \mathrm{~cm}$ long abnormal segment was present. There was a minimal

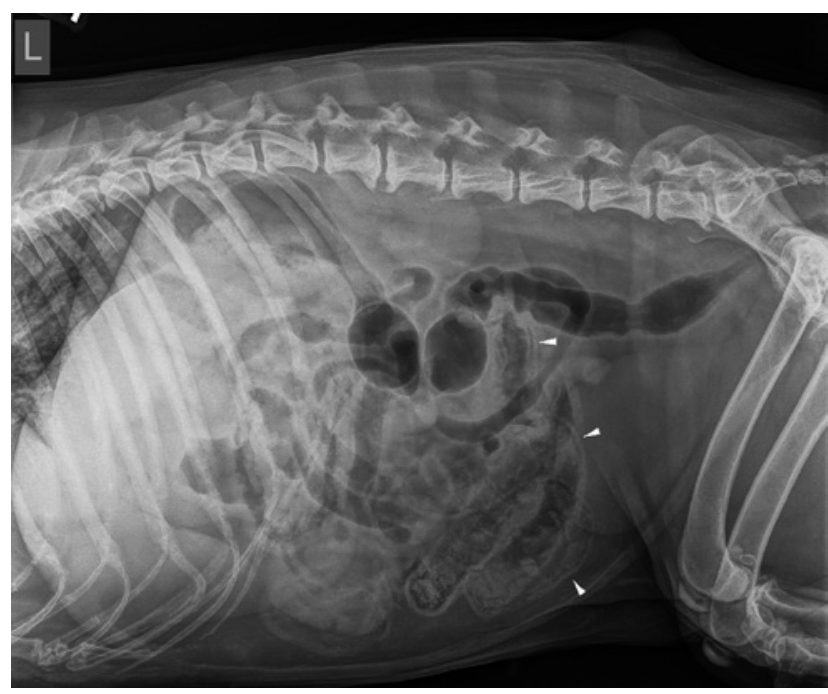

Figure 4. Left lateral radiograph of the abdomen showing gas lucencies within the small intestinal wall.

amount of abdominal free fluid noticed. The in total $66 \mathrm{~cm}$ abnormal looking segment was removed by enterectomy and end-to-end anastomosis. Cranial to this segment, a $30 \mathrm{~cm}$ piece of intestine with a thickening on the mesenteric side, was observed and left in place.

Histopathology demonstrated a pronounced multifocal hemorrhagic to ulcerative neutrophilic enteritis with the presence of a large number of bacteria described as short, gram-positive rods.

Parts of the intestinal wall were sent for bacterial culture and revealed the presence of $E$. coli. No fecal culture was performed.

\section{OUTCOME}

After surgery, the dog was monitored in the intensive care unit and was supported with omeprazole IV $1 \mathrm{mg} / \mathrm{kg}$ BID (Pantomed®, Takeda, Belgium), maropitant IV $1 \mathrm{mg} / \mathrm{kg}$ SID (Cerenia ${ }^{\circledR}$, Pfizer, Belgium), enrofloxacin IV $5 \mathrm{mg} / \mathrm{kg}$ SID (Baytril ${ }^{\circledR}$, Bayer, Germany), amoxicillin clavulanic acid IV $20 \mathrm{mg} / \mathrm{kg}$ TID (Augmentin ${ }^{\circledR}$, GSK Belgium, Belgium), methadone IV $0.2 \mathrm{mg} / \mathrm{kg}$ q4h (Comfortan ${ }^{\circledR}$, Dechra, the Netherlands) and crystalloids (ringer lactate, Braun, Germany). After receiving the results of the culture, enrofloxacin was discontinued. The dog developed severe pancreatitis post-operatively, but gradually recovered and was discharged seven days after surgery. One year after surgery, the dog was clinically doing well and did not show any symptoms anymore based on the owners' experience.

\section{DISCUSSION}

Pneumatosis is described as the presence of air or gas in abnormal locations in the body (Studdert et al., 2012) and has an uncommon but well-documented 
occurrence in humans. Pneumatosis most commonly involves the hepatic and portal venous system but can also involve other organs such as the bowel, in humans mostly the colon. Specifically, pneumatosis intestinalis is a rare, well-described radiologic finding in humans (Palamidessi, 2011). It has been reported as the presence of air or gas-containing cysts in the subserosal or submucosal layer of the small intestines (Degner, 1992; Aste et al., 2005; Song et al., 2013).

In human medicine, PI can be found in a wide range of clinical settings and has been reported in humans of all ages and both sexes (Heng et al., 1995; Takase et al., 2017). To the authors' knowledge, only two previous cases of PI in dogs (Song et al., 2013; Hedgespeth en Pérez, 2017), two cases in cats (Hutchinson et al., 2018; Walczak, 2018) and a case series of foals (Navas de Solis, 2012) have been described.

The pathogenesis of PI is still unclear, even in human medicine. Four hypotheses of etiopathology have been proposed suspecting either a mechanical, pulmonary, bacterial or mucosal damage origin (Aste et al., 2005; Degner, 1992; Hedgespeth and Pérez, 2017; Pear, 1998; Silveira et al., 2018). In the mechanical theory, an increase in the intraluminal pressure caused by mechanisms, such as intestinal obstruction, vomiting and diarrhea, ileus or endoscopy resulting in the dissection of gas into the intestinal wall through tiny defects or forcing gas through pre-existing ulcers into the intestinal mucosa is proposed. The pulmonary hypothesis has been formulated in patients with chronic obstructive pulmonary disease. Severe coughing may result in alveolar rupture and dissection of air along vascular channels in the mediastinum, tracking caudally to the retroperitoneum and then in the subserosa of the gastrointestinal tract (Ho et al., 2007; Degner, 1992; Pear, 1998; Choi et al., 2009). Alternatively, the bacterial model suggests that gas-producing bacteria enter the submucosal intestinal layer through areas of increased mucosal permeability or mucosal breaks, resulting in intramural gas formation (Degner, 1992; Pear, 1998; Aste et al., 2005; Choi et al., 2009). The mucosal damage theory on the other hand suggests that luminal gas under normal physiological pressure is forced into the gastrointestinal wall through injured mucosa (e.g. ulceration) (Silveira et al., 2018). However, PI is most likely caused by a combination of both mechanical and infectious factors (Pear, 1998; Gagliardi, 1996; Brown, 1999, Mitsuyoshi, 2015).

Two types of PI have been described in human medicine, called primary or benign PI and secondary or malignant (or life-threatening) PI. Those patterns can be distinguished from each other based on abdominal radiographs or computed tomography (Pear, 1998, Choi et al., 2009). This differentiation has been better described in the stomach and colon (Thierry et al., 2019). Primary PI creates a circular or cystic air pattern within the small intestinal wall, called the curvilinear pattern, which fits with pneumatosis cystoides intestinalis (Pear, 1998; Ho et al., 2007). The findings in the life-threatening form of PI consist with a linear pattern of gas within the small intestinal walls (Hwang et al., 2016; Rajan et al., 2017). Also, sometimes this form appears together with the presence of hepatic portal or porto-mesenteric venous air, which can be noticed on computer tomography (Sud et al., 1996; Ho et al., 2007, Hwang et al., 2016). A feature that is considered an additional sign of a malignant process is the unchanged presence and location of intramural gas upon changing patient position. (Sud et al., 1996, Fischetti et al., 2004). Although those signs can give an indication of the form which the body is dealing with, radiographic or computed tomography appearance alone does not allow the differentiation between the two in all cases (Pear, 1998; Ho et al., 2007).

Secondary PI can be associated with a variety of illnesses ranging from a fairly benign process to lethal ones (Hutchinson et al., 2018). The etiology of gastro-intestinal pneumatosis in dogs is mostly associated with intestinal neoplasia, ulcers, mucosal tears, maliciously introduced foreign bodies, bacterial overgrowth, gastric torsion, trauma, pulmonary disease, diabetes mellitus and iatrogenic mucosal injury (Aste et al., 2005; Hwang et al., 2016). The patient of the present report had no history of previous trauma, surgery or suspected foreign body ingestion. The clinical signs started acutely, and explorative laparotomy and histopathology results showed severe enteritis with intramural bacteria as the underlying cause.

Culture of the intestinal wall revealed the presence of E. coli. Although E. coli is part of the normal gastro-intestinal flora, it is equally plausible that they did not play a causative role in this dog's illness. The reported bacteria in the wall on histopathology (rods) could fit with clostridium species, which have been reported in association with gastro-intestinal pneumatosis in both human and veterinary medicine. The gold standard of diagnosis would be the confirmation with a fecal sample. Aerobic and anaerobic microbial cultures of feces, fecal smears, fecal flotation and the detection of clostridium perfringens enterotoxin in feces should be considered in case of suspicion of PI secondary to bacterial enteritis (Aste et al., 2005).

Symptoms which are commonly seen in human patients with PI are abdominal pain, nausea, vomiting, hematemesis, fever, chills, tachycardia, tachypnea (Guillén, 2015). The patient in this report showed signs of anorexia, lethargy, vomiting and abdominal pain, similar to the signs described in the two previous canine and two feline case reports (Hedgespeth and Pérez, 2017; Hutchinson et al., 2018; Song et al., 2013; Walczak et al., 2018).

On complete blood count, leukocytosis and mildmoderate non-regenerative anemia were noticed. The anemia in combination with hypoproteinemia was most likely secondary to the severe intestinal bleeding that was noticed on digital rectal examination and during surgery. Anemia has also been reported in other cases of PI previously described in the literature (Hedgespeth and Pérez, 2018; Hutchinson et al., 2018; Song et al., 2013; Walczak et al., 2018). 
In veterinary medicine, the first diagnostic tools to detect PI are usually abdominal radiography and ultrasonography. Computed tomography is considered the gold standard for establishing a definitive diagnosis in humans because it is the most sensitive imaging modality for the identification of small volumes of air within soft tissue (Di Pietropaolo, 2020; Ho et al., 2007). Computed tomography appears to be more sensitive than abdominal radiographs for the detection of hepatic portal and porto-mesenteric venous air, the presence of which can increase the suspicion of PI. The detection of hepatic portal or porto-mesenteric venous air can help distinguish benign causes of PI from lifethreatening causes of PI as the former has been shown to indicate transmural infarction (Ho et al., 2007).

Ultrasonographic findings of PI have been described as bright echoes within the layers of the small intestinal wall in humans (Aste et al., 2005), which were both seen in this case and in a dog and cat in other case reports considering PI (Hedgespeth and Pérez, 2018; Song et al., 2013; Walczak, 2018). However, differentiating intraluminal gas from intramural gas by ultrasonography may be difficult in some cases due to alteration of the normal appearance of the wall and severe acoustic interference of the gas (Song et al., 2013).

In humans, different therapies have been described for primary (benign) and secondary (life-threatening) PI. Treatment primarily includes resolution of the primary inciting cause. Therapy for life-threatening intestinal pneumatosis includes an aggressive medical and surgical treatment. Early explorative laparotomy is always indicated when there is a suspicion of necrotic bowel. Instead, aggressive medical management is warranted in non-surgical cases and includes hospitalization with intravenous fluids, antibiotics, analgesia and close monitoring. If the patient deteriorates during medical management, reimaging and exploratory laparotomy should be considered (Hutchinson et al., 2018). Therapies which have been described for benign gastro-intestinal pneumatosis are bowel rest, total parenteral nutrition and potentially broad-spectrum antibiotic treatment that includes anaerobic coverage (Aste et al., 2005; Fischetti et al., 2004 Guillén, 2015; Lang et al., 2011; Song et al., 2013).

Because of the uncommon presentation and the possibility of a foreign object or underlying neoplastic process, explorative laparotomy was elected in this case. Based on the severity of the jejunal lesions, enterectomy was performed and several samples were taken for histopathology.

\section{CONCLUSION}

In this care report, the imaging findings and treatment of a dog with secondary PI are reported. PI is an extremely rare disease in veterinary medicine and to the authors' knowledge, this is the first case report of a dog with secondary PI who survived after aggressive surgical and medical treatment.

\section{REFERENCES}

Aste G., Boari A., Guglielmini C. (2005). What is your diagnosis, Pneumatosis coli. Journal of the American Veterinary Medical Association 227, 1407-1408.

Brown M.A., Hauschildt J.P., Casola G., Gosink B.B., Hoyt D.B. (1999). Intravascular gas as an incidental finding at US after blunt abdominal trauma. Radiology 210, 405408.

Choi J.H., Kim T.E., Kim H.W., Seo J.M., Kim M.E., Yoon J.H. (2009). Pneumatosis coli in a dog. Journal of Veterinary Clinics 26, 298-302.

Degner D.A. (1992). Pneumatosis coli in a dog. The Canadian Veterinary Journal 33, 609-611.

Di Pietropaolo M., Trinci M., Giangregorio C., Galluzzo M., Miele V. (2020). Pneumatosis cystoides intestinalis: case report and review of literature. Clinical journal of Gastroenterology 13, 31-36.

Fischetti A.J., Saunders H.M., Drobatz K.J. (2004). Pneumatosis in canine gastric dilatation-volvulus syndrome. Veterinary Radiology and Ultrasound 45, 205-209.

Gagliardi G., Thompson I.W., Hershman M.J., Forbes A., Hawley P.R., Talbot I.C. (1996). Pneumatosis coli a proposed pathogenesis based on study of 25 cases and review of the literature. International Journal of Colorectal Disease 1, 111-118.

Guillén C., Jiménez F.J., Carrascosa T., Jover J.M. (2015). Emphysematous gastritis associated with portal venous gas: medical management to an infrequent acute abdominal pain. Revista Espagnola de Enfermedades Digestivas 107, 455-456.

Hedgespeth B.A., Pérez M.L. (2017). Pneumatosis intestinalis: what is your diagnosis?. Journal of the American Veterinary Medical Association 251, 37-39.

Heng Y., Schuffler M.D., Haggitt R.C., Rohrmann C.A. (1995). Pneumatosis intestinalis: a review. American Journal of Gastroenteroly 90 (10), 1747-1758.

Ho L.M., Paulson E.K., Thompson W.M. (2007). Pneumatosis intestinalis in the adult: benign to life-threatening causes. American Journal of Roentgenology 188, 16041613.

Hutchinson K.M., Tart K., Anderson K.L., Powell L.L. (2018). Pneumatosis of the intestines, colon and liver in a young cat. Veterinary Medicine and Science 4, 150-158.

Hwang T.S., Yoon Y.M., Noh S.A., Jung D.I., Yeon S.C., Lee H.C. (2016). Pneumatosis coli in a dog - a serial radiographic study: a case report. Veterinari Medicina 61 (7), 404-408.

Lang L.G., Greatting H.H., Spaulding K.A. (2011). Imaging diagnosis- gastric pneumatosis in a cat. Veterinary Radiology \& Ultrasound 52, 658-660.

Mitsuyoshi A., Hamada S., Tachibana T., Momono T., Aoyama H., Kondo Y., Inoguchi K., Yokoyama D., Nakay M., Suzaki S., Okabe H., Yanagibashi K. (2015). Pathogenic mechanisms of intestinal pneumatosis and portal venous gas: should patients with these conditions be operated immediately? Surgical Case Reports 1, 104.

Morris E.L. (1992). Pneumatosis coli in a dog. Veterinary Radiology \& Ultrasound 33 (3), 154-157.

Navas de Solis C., Palmer J.E., Boston R.C., Reef V.B. (2012). The importance of ultrasonographic pneumatosis intestinalis in equine neonatal gastrointestinal disease. Equine Veterinary Journal 44 (Supplement 41), 64.

Palamidessi N., Saul T. (2011). Pneumatosis intestinalis. The Journal of Emergency Medicine 40, 545-546. 
Pear B.L. (1998). Pneumatosis intestinalis: a review. Radiology 207, 13-19.

Rajan R., Maundura M., Wallace M. (2017). Pneumatosis intestinalis: a diagnostic dilemma. ANZ Journal of Surgery $87,155-156$.

Silveira C., Benigni L., Gugich K., McClaran J.K. (2018). Feline gastric pneumatosis. Journal of Feline Medicine and Surgery Open Reports 4 (2), 1-5.

Song Y.M, Lee J.Y., Lee J.W., Jeung W.C., Lee Y.W., Choi H.J. (2013). Ultrasonographic findings of pneumatosis intestinalis in a dog. Journal of Veterinary Clinics 30, 138-141.

Studdert V.P., Gay C.C., Hinchcliff K.W. (2021). In: Studdert V.P., Gay C.C., Blood D.C. (editors). Saunders Comprehensive Veterinary Dictionary. Fifth edition, Elsevier, Philadelphia, 868.

Sud Y.M., Lehl S.S., Bhasin D.K., Deodhar S.D. (1996). Emphysematous gastritis. American Journal of Gastroenterology 91, 604-605.
Takase A., Akuzawa N., Naitoh H., Aoki J. (2017). Pneumatosis intestinalis with a benign clinical course: a report of two cases. BMC Research Notes 10, 319.

Thierry F., Ferreira M.F., Paterson G.K., Liuti T., Del-Pozo J. (2018). Canine and feline emphysematous gastritis may be differentiated from gastric emphysema based on clinical and imaging characteristics. Journal of Veterinary Radiology \& Ultrasound 60 (2), 135-144.

Walczak R., Paek M., Jantra S., Amory J.T., Specchi S., Sanchez M. (2020). Radiography and ultrasonograpy of pneumatosis intestinalis in a cat. Veterinary Radiology \& Ultrasound 61, E26-E30.

\section{@creative}

C) 2021 by the authors. Licensee Vlaams Diergeneeskundig Tijdschrift, Ghent University, Belgium. This article is an open access article distributed under the terms and conditions of the Creative Commons Attribution (CC BY) license (http://creativecommons.org/licenses/by/4.0/).

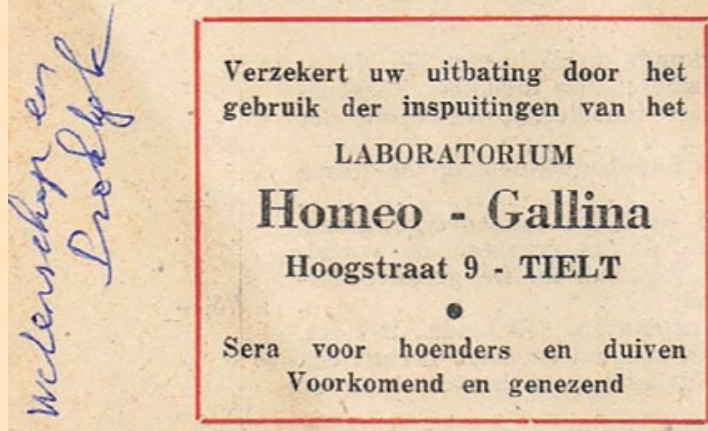

\section{Non Plus Ultra}

geneest en voorkomt met GROTE ZEKERHEID alle bacteriële besmettingen van luchtwegen en darmkanaal bij PLUIMVEE en DUIVEN.

Onfeilbaar ter genezing en voorkoming van COCCIDIOSIS en WORMEN.

Prijs per grote verpakking van 200 Pastillen: 65 Fr., franco per post tegen terugbetaling.

«HOLLANDS GLORIE », Heidebloemlei, 12 - SCHOTEN

Tel. 148.03

Drukkerij G. COOMANS \& A. DE STAERCKE. p. v. b. a.. 123, Nieuwlandstraat, Brussel 208 